\title{
Research on the Internal Marketing and the Corresponding Applications on Star Hotel Management
}

\author{
Junli Zhang \\ Xijing University, \\ Xi'an,Shaanxi,710123 China
}

\begin{abstract}
In this paper, we conduct research on internal marketing and corresponding applications on the star hotel management. The development of the economy hotel is in the exploratory stage in our country, with the rapid development of economy hotel, the management phase change, further market segmentation, brand further development, to further improve the management level will become the development direction of economy hotel in the future will inevitably exist in the development process problems, but with the increasing improvement of economy hotel and budget hotel, the new forms of mature, with its advantages and good development opportunity again these problems will be readily solved. Our research combines the concepts of internal marketing to propose the novel paradigm for the hotel management and market which holds special meaning.
\end{abstract}

\section{Keywords- Internal Marketing, Star Hotel, Management Mode, Corresponding Applications.}

\section{Introduction}

Hotel belongs to service industry, it is facing the main object of people, and services are intangible service, the service link is much, not only the contents of the service are more, the service need the flexibility of the demand is high, the hotel service is not static, and its primary purpose is to satisfy customer's requirement, so service in hospitality industry is changing as the requirement of customers, service time and service mode is unable to undertake unity, in such cases, the quality of the service personnel and management personnel and skills have higher requirements, the management methods of demand also exist differences and this also is the particularity of the hotel industry, in the virtually increased the difficulty of management [1-3].

Before casting our perspective, we should firstly analyze the characteristics of the hotel. (1) The complexity of hotel product. Hotel products and services of production and exchange process in time and space is unusually close to, and even can be said to be the same. Because of that it serves to show the complexity of the hotel product, and it also makes the hotel on the products and services in the business of encountered some problems. (2) Hotel widely associated with operating environment. Attaches great importance to the balance between the hotel and the market is particularly important, because with the development of market economy, the hotel industry is more and more fierce market competition, and to achieve the balance of the market development and hotel as the hotel enterprise must have three conditions: the correct management thought, the appropriate market strategy, hotel managers have to professional. (3) Comprehensive hotel management. As a manager should be fully aware of the material benefits of tangible and intangible combination of the spiritual enjoyment, is the guest really wants to get the ultimate interests. At the same time, the fine service must have a high quality service and it needs to have advanced and effective personnel training management system.

Management is to meet the need of basic modern management of mass production, and produce a comprehensive interdisciplinary. Hotel 
management is geared to the needs of the modern tourism, according to the situation of the development of the tourism culture support the party line policies, to meet the need of production, management, service the first line of the moral, intellectual, physical, beauty of all-round development from the aspects such as basic control of higher technology applied talents. Star hotel in the modern business management is a scientific systematic project and it not only needs to have new concepts and scientific management mode, and focuses on internal collaboration, which is also known as the team spirit. Internal marketing as a new concept of training, to ensure the effect of training work in two ways, first, it ensures that all levels of the employees, including senior management personnel, improve the consciousness of the service for the customer in environment to understand and implement business strategies and marketing activities. Secondly, it ensures that all employees under the premise of in the service for customers, to actively participate in the enterprise management and decision-making. The figure one demonstrates the concepts [4].

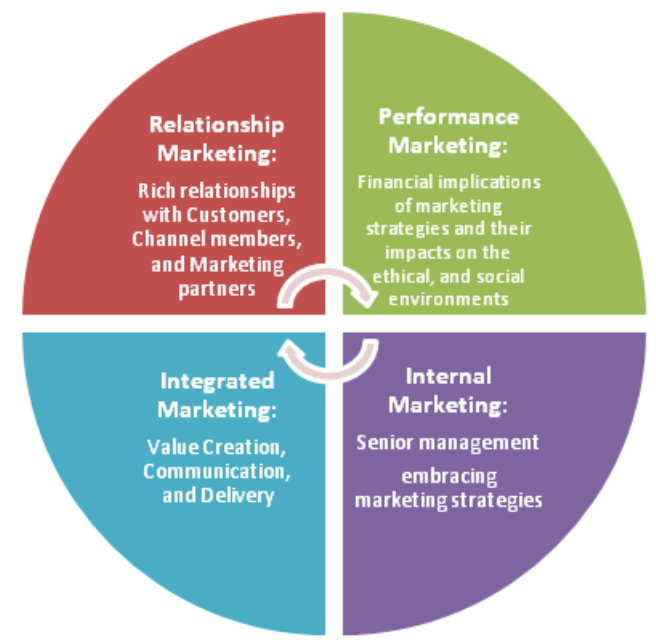

Figure 1. The General Components of the Internal Marketing

In this paper, we conduct research on the internal marketing and the corresponding applications on the star hotel management. In hotel management, often with a lot of changes, the management of the hotel staff not only face the changeable environment, roles, customers, employees face the constantly transformation, it process to manage a lot of inconvenience, so the changes on the hotel management, should focus on research in the case of change of hotel management methods, so it can increase the predictive and scientific management. In the later sections, we will discuss in detail.

\section{Our Proposed Methodology and Perspective}

The Basic Concept of the Enterprise Marketing. Marketing activities are always carried out in a certain environment and the environment for the marketing activities has a great role in promoting. Marketing to make enterprise market positioning strategy, under the guidance of market positioning strategy, product strategy and pricing strategy to win in the fierce market competition, we should use various ways to set up their brand image, in the quality of products, sales and after-sales service for the social identification of the enterprises and the products. From the angle of the responsible to the consumers, and constantly blaze the new trails to provide social resources saving, safe and convenient products to meet consumer demand [5-6].

Competition between enterprises is generally follow the same form of marketing, the vicious circle of price war, as a result, the homogeneity competition not only cause inefficient, and waste of social resources. Based on this, it is necessary for small and medium-sized enterprise marketing innovation model is discussed in order to attract the attention of the small and medium-sized enterprises. Small and medium-sized enterprises are sold to their own products or the services, expand the company's customers, increasing sales of a product or service quantity generally adopt the following strategies.

Pricing strategy. The cost of the enterprise directly decides the enterprise offer price space. Enterprises in the lowest quotation for the enterprise of the 
premise of the cost of a product or the service enterprise's highest price can withstand the market prices for consumers. The gap between the highest and the lowest price determines the scope of the enterprise adjust price.

Product strategy. Small and medium-sized enterprise target market is men's shoes in the market, because there is so much the number, if we provide a product or the service and other enterprises have homogeneity, the profit will be very low or even to the survive. Only provide differentiated product or service to the survival and development. Small and medium-sized enterprises should try to find somebody has no competition in the market areas.

Sales strategy. Market of small and the medium-sized enterprises with limited resources, marketing, generally choose a variety of channels, fully communication with customers, and ensure the channels, improve the efficiency of channel. Enterprise can conduct self-marketing by the agent on a commission basis, or by mail, telephone, television and the Internet to sell. The emergence of electronic business for small and medium-sized enterprises to provide a low cost efficient channel mode. A variety of marketing channels has different advantages and the disadvantages and chooses to suit oneself the best channel.

The Hotel Marketing. At present, Chinese hotel industry market competition gradually stepped into the stage of brand competition from price competition stage. The importance of brand and brand of value has been more and more hotel colleagues agree. Through continuous innovation, to enhance brand value, becomes the hospitality industry in one of the key means of market competition to win.

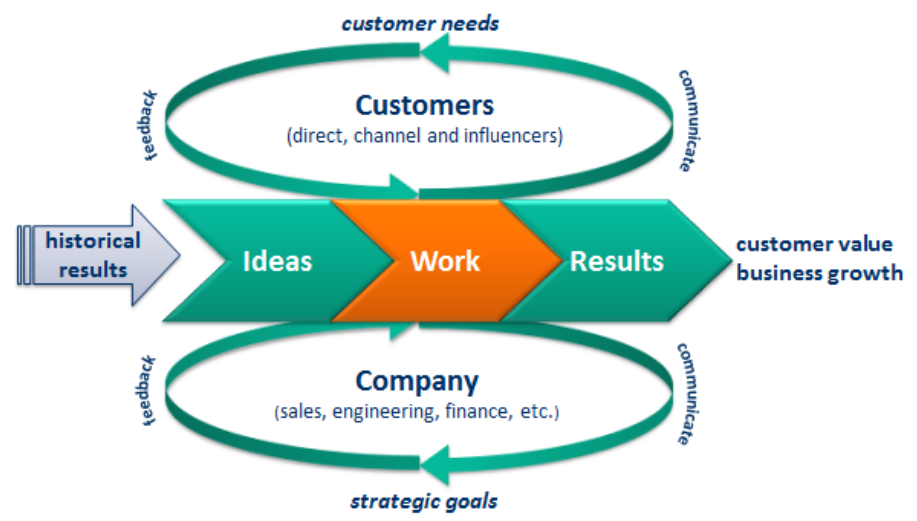

Figure 2. The Hotel Marketing and the Systematic Strategy

After several years of rapid development of the industry's investment and management gradually tend to be more rational, diversification of demand led to the strengthening of market segmentation, some of the new product type began to emerge. On business tourism market demand, driven by the demand for economy hotel product innovation and market segmentation, began to derive a variety, each has its characteristics of hotel types. This article through to the economy hotel overview of the tourist market, the classification of demand diversity, and the features of market analysis, summarized the current development of China's economy hotel, think in market demand and industry investment, driven by factors such as product innovation economy hotel is years mainstream of development trend in the future. Correspondingly, the marketing tips can be organized as the following aspects. 
Provide satisfactory hotel products and service to achieve customer requirements. Hotel for a specific target market groups and consumer demand characteristics, design the corresponding hotel products, and in the actual operation according to the opinions of the guests continuously adjust and modify, to constantly improve, so as to fully meet the needs of the guests [7].

Provide information channel to increase communication with the customer. The hotel must be unobstructed channels of the communication with the guests. The latest requirements so as to accurately grasp the guest, and the satisfaction of the product.

Provide additional benefits to the guests to discount. Consumer is buying the hotel product is revolves around two kinds of interests, the interests is the core of the product itself and it is to buy time, place, quantity and additional benefits brought by brand. Overall customer value, including customer be all interests in the process of purchasing and consumption.

The Hotel Management Characteristics. As a reusable component part of the service industry, the person is the direct object of hotel service activities, has the high standards and requirements of the quality of service. Service quality is directly related to the economic benefits of the hotel and the long-term development and the service quality directly depends on the hotel staff service skills and service consciousness. Therefore, in the hotel industry, talent becomes the main competition content. Under the huge pressure of the competition, the hotel in the management process requires scientific human resources management, attaches great importance to improve the hotel staff service skills and service consciousness. The corresponding method and the measures to encourage service personnel to improve their service level unceasingly, to provide efficient, high quality service, improve economic efficiency and social hotel reputation.

Accordingly, the management should pay attention to the listed aspects. (1) Intelligent facilities. With the advent of the era of high-tech, the guests of the hotel's facilities gradually all put forward higher request, driven development in the direction of the intelligent room facilities. (2) Type of the diversification. Along with the development of the hotel industry, some far-sighted hotel has already begun to build their own characteristics, and the type of room is different from other hotel one of the important ways, as a result, makes the room type presents the development trend of diversification. (3) Guest room green. In advocating for the sustainable development of today, to create green hotel has become a kind of fashion and the greening of guest room is one of very important components. (4) Enrichment of the project. Room service program of the establishment of both and not limited to the class, such as the star limited, but taking into full consideration the needs of the guests and the hotel's actual situation, make the goal of services tend to be more colorful. Even the same services, efforts to form the service feature of the hotel. 


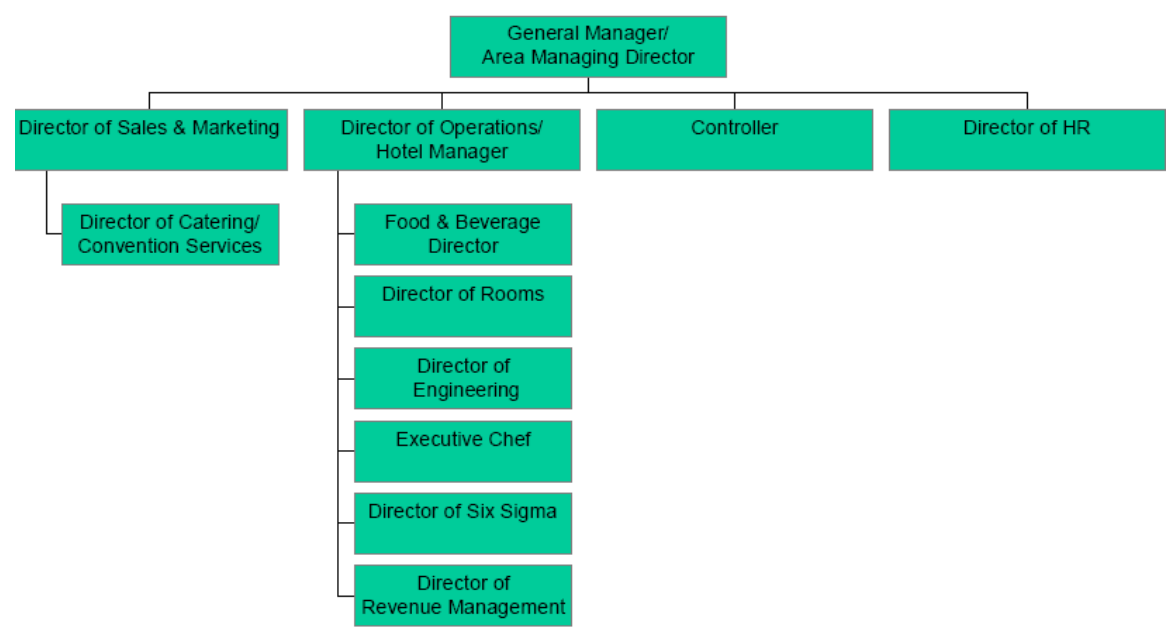

Figure 3. The Architecture of the Modern Hotel Management Team

The Internal Marketing. Origin and development of the internal marketing that is based on the assumption that: satisfied customers satisfaction of staff, to win customer satisfaction, employee satisfaction in first place. Early internal marketing researchers understanding of internal marketing is to employees as internal customers, their definition of internal marketing is: to sell the company to internal employees, customers high satisfaction of employee will lead to the market-oriented and the customer-focused, effective service delivery requirements that has motivated and customer oriented consciousness of employees. Internal marketing theory in the early stage of development, most of the literature are focused on the discussion of employee motivation and employee satisfaction, internal marketing was first used as a way to improve the quality of service delivery organization [8].

Since there is social and economic exchange internal marketing, in most cases, the value of social exchange are assumed to be rational, it to social mainstream moral value and interpersonal principles as the foundation; Economic exchange obey the instrumental rationality, it based on the enhanced self-interest. How belong to limited exchange, exchange of economy and the social exchange may be linked with extensive exchange. Therefore, we should follow the listed suggestions. (1) Timing of the brand is critical to the success of the internal marketing, because the person is a repulsive force for change in nature most of the people to change the tolerance are limited as the change of the brand is no exception. (2) Internal and external brand marketing brand marketing goals have the similar goal: make the employees have an emotional connection to the company. If we want to achieve such a goal, managers need to do is to make employees throughout the emotional connection to their daily routine. (3) Managers can plan and execute a brand movement within the company, and then put the brand information to infiltrate every corner of the company. Perform the brand movement can draw lessons from the practice of customer marketing, a series of phases and steps, research, planning, execution, feedback, etc. to make the employees believe that the advantages and reliability of the brand.

\section{Conclusion}

In this paper, we conduct research on the internal marketing and the corresponding applications on the star hotel management. Internal marketing of the hotel is to apply marketing theories and ideas to staff within the hotel, the staff as a "customer", to provide staff to the satisfaction of the service, so as to stimulate the staff's work enthusiasm and enhance the external marketing awareness of employees, to motivate them to do the best result and improve the quality of the service. In internal marketing, the purpose of training is to make 
staff of the hotel have a comprehensive understanding and determine their position in it, clear the relationship with other employees and the relationship with customers. In the recent future, we will apply our proposed methodology into the real world scenarios to verify the effectiveness of the marketing paradigm.

\section{References}

[1] Kara, Derya, Muzaffer Uysal, and Vincent P. Magnini. "Gender differences on job satisfaction of the five-star hotel employees: the case of the Turkish hotel industry." International Journal of Contemporary Hospitality Management 24.7 (2012): 1047-1065.

[2] Mao, Zhenxing Eddie, and Yang Yang. "FDI spillovers in the Chinese hotel industry: The role of geographic regions, star-rating classifications, ownership types, and foreign capital origins." Tourism Management 54 (2016): 1-12.

[3] Sun, Sunny, Rob Law, and Tony Tse. "Exploring price fluctuations across different online travel agencies A case study of room reservations in an upscale hotel in Hong Kong." Journal of Vacation Marketing (2015): 1356766715592663.
[4] Chawla, Niran, and Montri Wiboonrat. "Information Transfer Model in Hotel Chain Management." The 12th Int. Conf. on e-Learning, e-Business, Enterprise Information Systems, and e-Government, Las Vegas, USA. 2013.

[5] Pereira-Moliner, Jorge, et al. "Quality management, environmental management and firm performance: direct and mediating effects in the hotel industry." Journal of Cleaner Production 37 (2012): 82-92.

[6] Karatepe, Osman M., and Behnaz Gharehbaghi Douri. "Does customer orientation mediate the effect of job resourcefulness on hotel employee outcomes? Evidence from Iran." Journal of Hospitality and Tourism Management 19 (2012): e13.

[7] Lei, Wu. "SWOT Analysis of Nanchang Five-Star Hotel-A Case Study of Jinfeng Hotel." Science Mosaic 7 (2012): 067.

[8] Aguilar-Rojas, Oscar, Carmina Fandos-Herrera, and Carlos Flavián-Blanco. "What may lead you to recommend and revisit a hotel after a service failure instead of complaining?." International Journal of Contemporary Hospitality Management 27.2 (2015): 214-235. 